\title{
Diagnostic Problems and Advances in Inflammatory Bowel Disease
}

\author{
Robert Odze, M.D., F.R.C.P.C. \\ Department of Pathology, Brigham and Women's Hospital, Boston, Massachusetts
}

This review summarizes current diagnostic problems and advances with regard to patterns of inflammation and dysplasia in ulcerative colitis and Crohn's disease. Ulcerative colitis and Crohn's disease have a variety of characteristic but non-specific pathologic features. In approximately $5 \%$ of inflammatory bowel disease cases, a definite diagnosis of ulcerative colitis or Crohn's disease cannot be established, in which case the term "indeterminate" colitis is used. Most cases of indeterminate colitis are related to fulminant colitis, a condition in which the classic features of ulcerative colitis or Crohn's disease may be obscured by severe ulceration with early superficial fissuring ulceration, transmural lymphoid aggregates, and relative rectal sparing. Approximately $20 \%$ of patients with indeterminate colitis develop severe pouch complications, which is intermediate in frequency between ulcerative colitis (8-10\%) and Crohn's disease (30-40\%). In order to establish a diagnosis of ulcerative colitis or Crohn's disease, it is important to evaluate pathologic material in conjunction with clinical, laboratory, radiologic, and endoscopic features and to recognize the variety of changes that may be seen in fulminant ulcerative colitis.There are a number of exceptions to the classic principles of inflammatory bowel disease pathology that may lead to diagnostic confusion. For instance, apparent skip lesions on biopsy analysis may occur in patients with ulcerative colitis in the following settings; long term oral or topical therapy, focal ascending colon, cecum and/or appendiceal involvement in patients with left sided ulcerative colitis, upper gastrointestinal involvement in patients with ulcerative colitis, and at initial presentation of ulcerative colitis in pediatric patients. In all of these circumstances, the finding of patchy disease and/or rectal sparing should not be misinterpreted as either evi-

Copyright (C) 2003 by The United States and Canadian Academy of Pathology, Inc.

VOL. 16, NO. 4, P. 347, 2003 Printed in the U.S.A.

Date of acceptance: January 8, 2003.

Address reprint requests to: Robert D. Odze, M.D., F.R.C.P.C., Director, GI Pathology Service, Department of Pathology, Brigham and Women's Hospital, 75 Francis Street, Boston, MA 02115; fax: 617- 277-9015, e-mail: Rodze@partners.org.

DOI: 10.1097/01.MP.0000064746.82024.D1 dence against a diagnosis of ulcerative colitis, or as representing skip areas characteristic of Crohn's disease.Patients with ulcerative colitis and Crohn's disease are at increased risk for the development of dysplasia and carcinoma. Recent studies suggest that given a similar duration and extent of disease, patients with Crohn's disease have a similar risk of dysplasia and cancer as patients with ulcerative colitis. Dysplasia in ulcerative colitis may be classified as flat or elevated (dysplasia associated lesion or mass [DALM]). Patients with flat high grade dysplasia are generally treated with colectomy. However, there is recent evidence to suggest that patients with flat low grade dysplasia, particularly if detected at the time of initial endoscopic exam, or if its multifocal or synchronous, should also be treated with colectomy. Elevated lesions in ulcerative colitis (DALM) are subdivided into "adenoma-like" and "non-adenoma-like" lesions based on their endoscopic appearance. Recent data suggests that adenoma-like lesions, regardless of the grade of dysplasia, or the location of the lesion (i.e., inside or outside areas of established colitis) may be treated adequately by polypectomy if there are no other areas of flat dysplasia in the patient. Although there are some histologic and molecular features that can help differentiate sporadic adenomas from adenoma-like polypoid dysplastic lesions related to ulcerative colitis, none of these adjunctive techniques can help distinguish these lesions definitively in any single patient. Patients with a non-adenoma-like DALM, (irregular, broad based, or strictured lesion) should be treated with colectomy because of the high probability of adenocarcinoma. The surveillance and treatment options for patients with flat and elevated dysplasia in ulcerative colitis are reviewed in detail.

Mod Pathol 2003;16(4):347-358

Ulcerative colitis (UC) and Crohn's disease (CD) are the two most common forms of chronic inflammatory bowel disease (IBD). Unfortunately, the pathogenesis of these disorders is unknown (1-4). As a result, there are no specific clinical or laboratory features that may help establish a diagnosis. Thus, diagnosis of UC and CD relies heavily on pathologic in- 
terpretation of biopsy and resection specimens $(1,4)$. Since both UC and CD have a variety of characteristic, but non-specific (non-pathognomonic) pathologic features, it is important to evaluate pathologic material in conjunction with clinical, laboratory, radiologic and endoscopic features $(1,2)$. A summary of the classic microscopic features of UC and CD is noted in Table 1. Important features of untreated UC in biopsy specimens include diffuse involvement of the colorectum without skip lesions, lack of submucosal involvement, lack of granulomas (except those related to mucin or foreign bodies), and lack of terminal ileum involvement (with the exception of a minor degree of inflammation associated with backwash ileitis). In resection specimens, diffuse continuous mucosal disease (including the rectum), in the absence of deep fissuring ulceration, sinus tract formation, transmural lymphoid aggregates (away from areas of ulceration), small intestinal involvement (except in backwash ileitis) or granulomas, in the appropriate clinical, radiologic, and endoscopic setting, are findings normally considered consistent with UC. Typical features of $\mathrm{CD}$ include segmental involvement, less severe disease in the distal colon compared to the proximal colon, rectal sparing, submucosal inflammation, patchiness of inflammation, granulomas unrelated to mucin or foreign bodies, terminal ileum involvement, upper GI involvement, and a less pronounced degree of mucosal architectural changes, and mucin depletion, compared to UC. Under normal circumstances, any of these features should be considered sufficient for a diagnosis of CD (Fig. 1). However, in some cases, a definite diagnosis of UC or CD cannot be made due to overlapping features ("Indeterminate colitis"). Furthermore, several exceptions to the "classic" pathologic features outlined above (and in Table 1) do exist and may cause diagnostic confusion. These issues are discussed further below

\section{Indeterminate Colitis}

\section{Definition}

In approximately $5 \%$ of IBD cases, a definite diagnosis of UC or CD cannot be established due, most commonly, to either insufficient clinical, radiologic, endoscopic or pathologic data, or because

TABLE 1. Classic Microscopic Features in Untreated Ulcerative Colitis and Crohn's Colitis (Hard Criteria)

\begin{tabular}{ll}
\hline \multicolumn{1}{c}{ Ulcerative Colitis } & \multicolumn{1}{c}{ Crohn's Disease } \\
\hline Diffuse, continuous disease & Segmental disease \\
Rectal involvement & Variable rectal involvement \\
Disease worse distally & Variable disease severity \\
No fissures & Fissures, sinus, fistula \\
No transmural aggregates & Transmural lymphoid aggregates \\
No ileal involvement (exception: & Ileal involvement \\
"backwash") & \\
No granulomas & Upper GI involvement \\
\hline
\end{tabular}

of prominent overlapping features between these two disorders (5-8). Under these circumstances, the term "indeterminate" colitis (IC) has been used. However IC is not a disease entity and has no diagnostic criteria. Rather, it represents a provisional descriptive term to be used by pathologists' only when he or she is unable to establish a definite diagnosis given the information available at the time of surgical sign out. In fact, in up to $80 \%$ of cases, the true nature of the patient's underlying IBD usually becomes apparent within a few years (9).

\section{Diagnosis}

Historically, the term IC was originally applied to cases of fulminant colitis (i.e., severe colitis with systemic toxicity and often associated with colonic dilatation), a disease in which the classical features of UC may be obscured by severe ulceration with early superficial fissuring ulceration, transmural lymphoid aggregates, and relative rectal sparing, features normally associated with CD (10) (Fig. 2). However, more recently, the term has been used to describe any IBD case in which a definite diagnosis cannot be established. Naturally, the prevalence of establishing a "diagnosis" of IC is highly dependent on the level of awareness of the reviewing pathologist regarding the wide range of morphologic features that can be seen in IBD. For instance, in a recent study by Farmer et al., 84 IBD colectomy specimens were reviewed by 24 university pathologists and the diagnostic accuracy was compared to a single GI pathologist who has a particular interest in IBD (7). Not unexpectedly, the GI pathologist rendered a diagnosis that was different from the others in $45 \%$ of specimens, and in most cases, it resulted in a change of diagnosis from UC to CD. In most instances, cases termed IC are usually UC, but a variable proportion (10-40\%) turn out to be CD. Rarely, other pathologic mimics of IBD, such as NSAIDs colitis, diverticular disease-associated colitis, radiation or ischemic colitis, or infectious colitis may be interpreted as IC (4). Unfortunately, there is a strong clinical need to classify IBD patients definitively as CD or UC (or other), since an ileal pouchanal anastomosis (IPAA) "pouch" procedure is generally contradicted in $C D$ due to a high risk of morbidity related to pouchitis, fistulas, incontinence or anastomosis leaks $(6,7,11,12)$. In 1998, Swan et al. evaluated 95 cases of "fulminant colitis" (IC) with the aim of identifying features that can help separate UC from CD (10). After a comprehensive review of all pathologic material and clinical follow up information, microscopic examination correctly diagnosed UC or CD in $91 \%$ of cases. Interestingly, granulomas and transmural lymphoid aggregates away from areas of ulceration were the most specific indicators of CD. 
The most common reasons for rendering a diagnosis of IC are noted in Table 2. In addition to those discussed above, pathologists often fall back on a diagnosis of IC when a definite diagnosis of UC or CD cannot be made on biopsy analysis, a practice which is highly discouraged. In other instances, the diagnosis is used because of a lack of awareness regarding unusual variants of UC that can lead to apparent "skip" lesions in UC, or because of the unwillingness of pathologists to accept certain hard core criteria, such as segmental disease, granulomatous inflammation, transmural lymphoid aggregates, or deep fissuring ulceration as solitary criterion for $\mathrm{CD}$.

\section{Outcome}

There have been many studies that have evaluated the pathologic features, natural history, and outcome of ileo-anal pouches in patients with IC (6, $8-18)$. However, the results vary considerably due to the fact that most of these studies are retrospec-

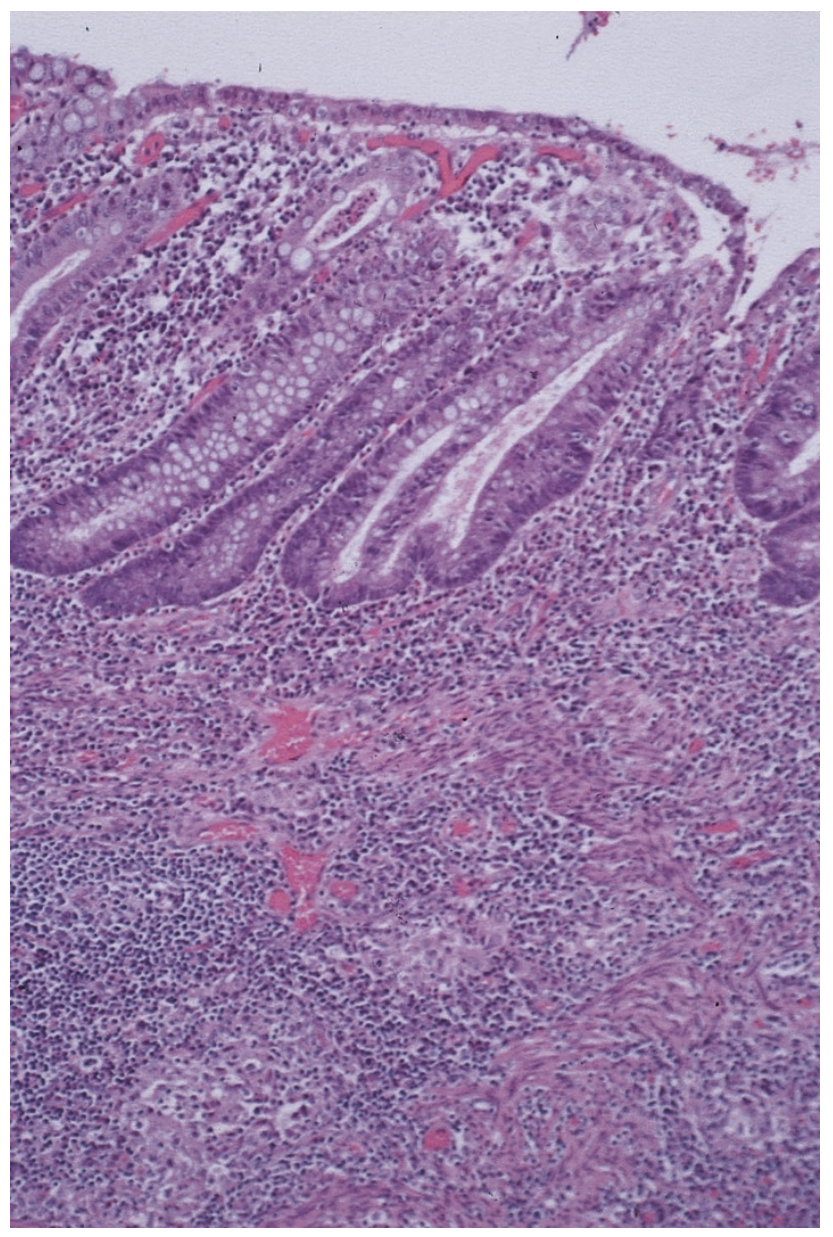

FIGURE 1. Medium power view of a section of colon from a patient with Crohn's disease. The mucosa shows crypt architectural distortion and an increased amount of acute and chronic inflammation in the lamina propria. The inflammation extends into the deep mucosa and superficial submucosa. Non-necrotizing granulomas are present both in the superficial mucosa and in the submucosa.
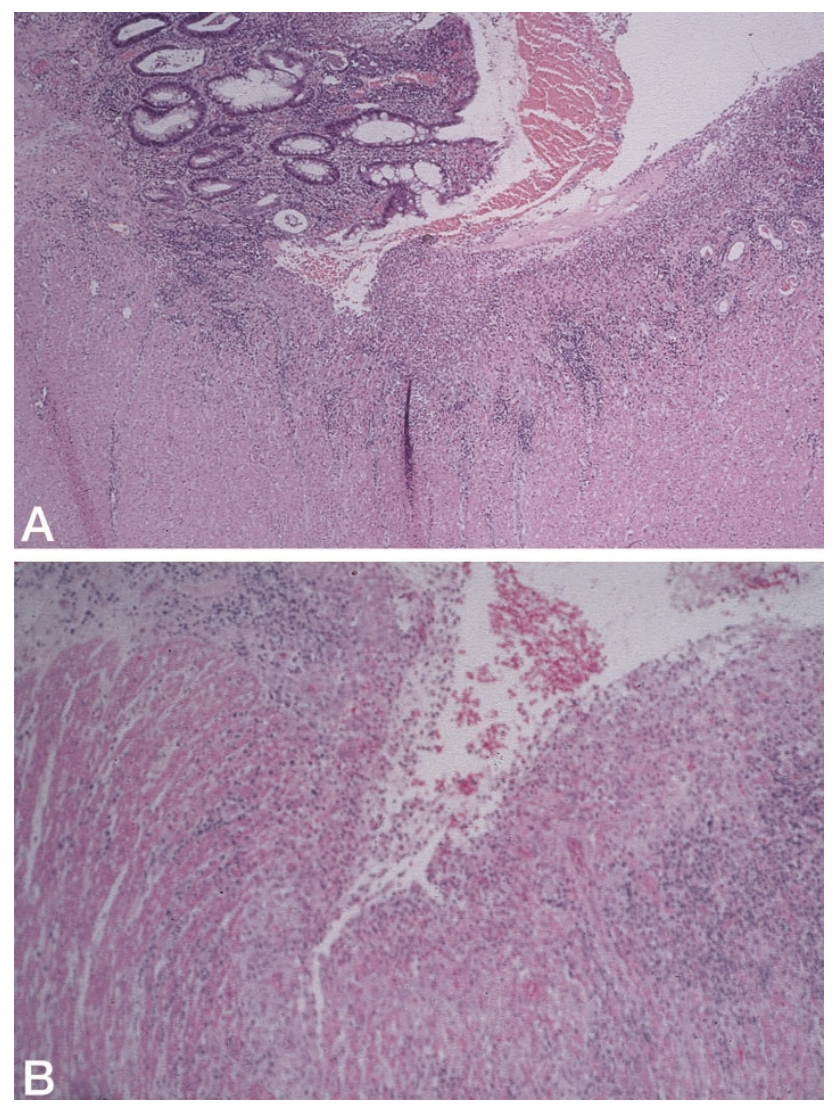

FIGURE 2. A, Low power view of a section of colon from a patient with fulminant ulcerative colitis. The mucosa shows severe chronic active inflammation and ulceration extending into the deep portions of the mucosa and superficial muscularis propria. B, In a patient with fulminant colitis, early superficial fissuring ulceration, as seen in this photograph, may occur rarely.

tive, have varying and undefined criteria for IC, and lack sufficient follow-up information. Nevertheless, in general, approximately $20 \%$ of IC patients develop severe pouch complications, which is intermediate in frequency between that seen in UC (8$10 \%)$ or $\mathrm{CD}(30-40 \%)(6,8,11,14,16)$. This is expected given that in most studies, the IC study group is composed of a mixture of true UC and CD patients. In a recent study by Yu et al. of 82 cases of IC and 1,437 cases of UC, all of whom had an IPAA operation, patients with IC had a higher incidence of pelvic sepsis, pouch fistulas and pouch failure in comparison to UC patients (6). However, ultimately, $15 \%$ of IC patients had their diagnosis changed to $\mathrm{CD}$, and when the $\mathrm{CD}$ patients were removed from the analysis, the rate of pouch complications in IC and UC patients was similar. Similarly, in another study by McIntyre et al. in 1995, 71 cases of IC and 1,232 UC patients were compared for frequency of bowel movements, incontinence or prevalence of pouchitis and pouch failure (14). Although the failure rate in IC was higher than UC (19 vs. $8 \%$ ), overall, the IC patients had a similar outcome as UC, suggesting again that most patients 
TABLE 2. Common Reasons for Making a Diagnosis of Indeterminate Colitis

1. Fulminant colitis (fissures, transmural inflammation, rectal sparing in UC)

2. Insufficient clinical, radiologic, pathologic information

3. Interpretation of mucosal biopsy specimens

4. Failure to recognize unusual variants of UC and CD UC with

Relative rectal sparing

Superficial fissure

Granulomas related to ruptured crypts

Right sided involvement in left sided colitis

Appendiceal involvement

Backwash ileitis

Therapy effect

CD with diffuse mucosal involvement

5. Failure to utilize hard criteria for CD

Transmural inflammation

Granulomas

Deep fissuring ulceration

Ileal involvement

Segmental disease

6. Presence of secondary disease (for example, pseudomembranous colitis, ischemic colitis, infection)

with IC probably have UC. Interestingly, although a substantial proportion of CD patients who receive an IPAA operation develop pouch failure $(30-45 \%)$, some recent studies suggest that there is quite acceptable pouch function in $\mathrm{CD}$ patients whose pouches can be retained in situ $(11,13)$.

\section{Diagnostic Tests}

In certain circumstances, serologic testing for anti-neutrophil cytoplasmic antibodies (ANCA) and anti-saccharomyces cerevisiae (ASCA) antibodies may be helpful in classifying IC cases into UC or CD (19). For instance, ANCA are detected in the serum of $60-70 \%$ of UC patients, but in only $10-40 \%$ of $\mathrm{CD}$ patients. Interestingly, of the $\mathrm{CD}$ patients who are ANCA positive, most have left-sided colitis with clinical, endoscopic and/or histologic features of UC. ASCA are present in $50-60 \%$ of CD patients, and has a sensitivity of $67 \%$ and a specificity of $92 \%$ as a serum marker for $\mathrm{CD}$. Unfortunately, the use of ANCA and ASCA in IC has not been extensively studied, and needs further investigation.

\section{Unusual Morphologic Variants of Ulcerative Colitis and Crohn's Colitis}

There are a number of exceptions to the "classic" principles of IBD pathology that my lead to diagnostic confusion. A summary of the causes of unusual morphologic patterns of disease in UC is noted in Table 3. It is important for pathologists to recognize these variants in order to avoid falling into a diagnostic trap.

\section{Effect of Oral and Topical Therapy}

Classic teaching emphasizes that chronic UC is characterized morphologically by the presence of
TABLE 3. Summary of Causes of Unusual Patterns of Disease in UC

1. Treatment effect

2. Low grade disease in remission

3. Appendiceal involvement

4. Cecum/ascending colon inflammation in left-sided colitis

5. Pediatric UC (initial presentation)

6. "Backwash" ileitis

7. Rare UGI involvement (i.e., duodenitis)

8. Fulminant colitis

diffuse fixed architectural and/or cellular mucosal changes that categorize the process as chronic. However, in 1993, Odze et al. prospectively evaluated 123 rectal mucosal biopsies from 14 patients with pathologically confirmed UC treated with either 5 ASA or placebo enemas (20). Overall, over the course of treatment, $29 \%$ of rectal biopsies from $64 \%$ of patients were histologically normal showing no evidence of chronic or active disease. In fact, patients treated with 5 ASA showed a significantly higher percentage of normal biopsies (obtained from areas of mucosa previously shown to be involved with chronic-active disease) in comparison to the placebo group (Fig. 3). This was the first report to demonstrate that "fixed" chronic features in UC may revert to normal in the natural course of the patient's illness, and that this phenomenon may be enhanced by topical therapy. Subsequent studies by Kleer et al., Bernstein et al. and Kim et al., all of whom evaluated patchiness of disease and patterns of involvement in UC colorectal biopsies with time, confirmed and expanded the initial findings by Odze et al. (21-23). In these studies, 30-59\% of patients, some of whom were treated with oral sulfasalazine and/or steroids, showed either patchiness of disease or rectal sparing in their follow-up biopsies. For instance, in a study by Kim et al., $27 \%$ of follow-up endoscopies in $59 \%$ of patients showed either patchy (microscopic areas of skip lesions) disease, rectal sparing, or both during the follow up interval (23). Awareness of these data should prevent the finding of a normal rectal biopsy, or patchiness of disease, in treated UC patients from being misinterpreted as either evidence against this diagnosis or as representing focal skip areas characteristic of CD. In addition, patients with low-grade indolent disease, particularly those in clinical and pathologic remission, may also show minimal architectural features of chronicity, or perhaps even a completely normal biopsy appearance, during the natural waxing and waning course of their illness. However, it is important to realize that these data relate primarily to biopsy material from treated patients. It does not apply to patients who present initially before treatment, or in whom a diagnosis is being considered from evaluation of a resection specimen. Large portions of mucosa from a resection specimen that show a normal histologic ap- 
pearance is an indication of true segmental disease and would normally provide reliable evidence in support of an alternative diagnosis such as CD.

\section{Ascending Colon, Cecum, and Appendiceal Involvement as "Skip" Lesions in UC}

Some patients with either subtotal or left-sided colitis may show patchy, mild, cecum and/or ascending colon chronic-active inflammation which may be falsely interpreted as CD due to the impression of segmental involvement (24-27). In fact, up to $65 \%$ of UC patients present initially with limited left-sided involvement, which may spread to involve more proximal portions of the colon in 29$58 \%$ of cases $(24,28,29)$. In one study by D'Haens et al. of 20 patients with established left-sided UC, 6 showed a sharp demarcation between affected and unaffected portions of colon, whereas 14 showed a more gradual transition (24). The area of transition may appear somewhat patchy and give the false impression of skip lesions. Furthermore, $75 \%$ of the latter group of patients showed an area of inflammation in the cecum, primarily in the periappendiceal mucosa, that was separate in space from the distal inflamed segment. In a previous study by our group, 14 patients with both left-sided UC and pathologically confirmed patchy right-sided chronic inflammation were compared to 35 control patients with limited left-sided UC only (27). These two groups of patients showed similar demographic features, extra-intestinal manifestations, severity of disease, prevalence of extension to pancolitis, and natural history which suggests that patchy rightsided inflammation in patients with left-sided colitis has little clinical significance but should be recognized by pathologists to prevent a false diagnosis of CD in this setting.

Similarly, since the original description by Davison et al. in 1990 of discontinuous involvement of the appendix in $21 \%$ of 62 cases of UC (30), several other studies have shown that the appendix may be involved as a "skip" lesion in this disease $(31,32)$, although at least one other study has failed to confirm this finding (33). In another study by Groisman et al., ulcerative appendicitis was present in $86 \%$ and $87 \%$ of patients with non-universal and universal UC, respectively (31). In fact, this study contained two cases with limited left sided involvement combined with appendiceal involvement. In summary, both appendiceal and/or cecum/ascending colon involvement may occur in patients with subtotal colitis and should be recognized as a potential "skip" lesion in UC.

\section{Initial Presentation of Pediatric Patients with UC}

Several recent studies have shown that pediatric patients who present initially with untreated UC may show evidence of relative, or complete, rectal sparing or even patchiness of disease (34-39). For instance, in one study by Markowitz et al. of 12 pediatric patients with untreated UC, 5 (42\%) showed patchy, mild active inflammation and mild crypt changes in the rectum in comparison to more proximal colonic biopsies (33). In fact, one patient had a completely normal rectal biopsy. More recently, a large study by our group presented at the 2002 USCAP meeting by Glickman et al., compared the rectal mucosal biopsy appearance of 70 pediatric UC patients to 44 adult patients, all at initial presentation (35). In comparison to adults, the pediatric group showed significantly fewer cases with chronic active disease, and more patients with microscopic skip areas and relative rectal sparing in comparison to adults. Two of the 70 pediatric patients showed completely normal rectal biopsies at initial presentation in contrast to none of the adult patients. Thus, the absence of features of chronicity, mild active disease, and microscopic skip areas, at initial presentation in pediatric patients, does not exclude the possibility of UC.

\section{Backwash Ileitis}

It is commonly recognized that patients with severe pancolitis may show a mild degree of active inflammation in the distal few centimeters of terminal ileum which is presumably related to reflux of colonic contents $(40,41)$ (Fig. 4). This is termed "backwash" ileitis. This condition should not be confused with $\mathrm{CD}$ of the terminal ileum which more typically shows longer lengths of involvement and is normally associated with chronic active inflammation, and other features of CD such as fissuring ulceration, granulomas, and transmural lymphoid aggregates (41). Unfortunately, strict histopathologic criteria for backwash ileitis have not been defined. In fact, studies regarding the morphology of backwash ileitis date back to the 1960 s, and, thus, is a topic in need of re-evaluation. Although backwash ileitis has not been shown to be a significant risk factor for the development of pouchitis, rarely, premalignant dysplastic changes, and even adenocarcinoma, has been show to develop in this setting $(42,43)$. In fact, one recent study by Heuschen et al. showed a strong association of backwash ileitis with the development of colorectal cancer in patients with UC who have undergone proctocolectomy (44). In their study, colorectal cancer was found in $29 \%$ of 107 pancolitis patients with backwash ileitis, compared to $9 \%$ of patients without backwash ileitis and $1.8 \%$ of patients with limited left sided colitis. However, even in that study, discrete pathologic criteria for backwash ileitis were not defined. 

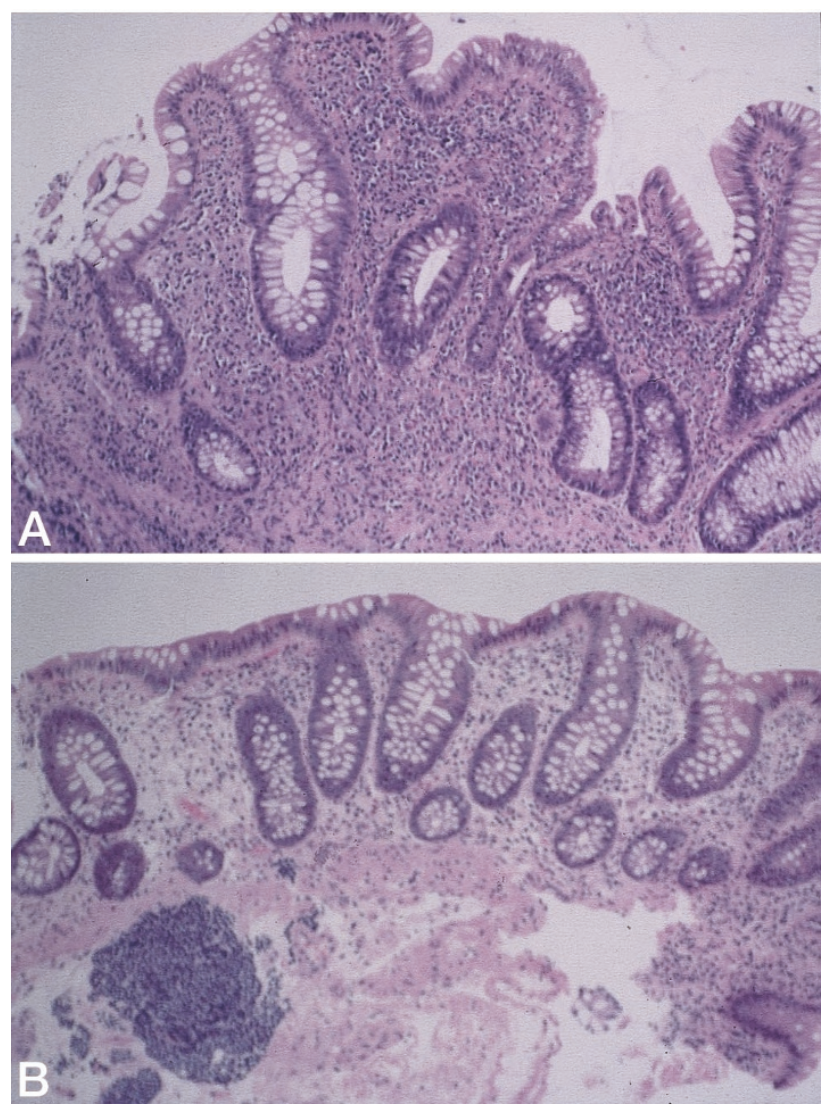

FIGURE 3. A, Biopsy of a patient with long standing ulcerative colitis showing chronic active colitis characterized by crypt architectural distortion and increased inflammation in the lamina propria. B, This biopsy is from the same area of the colon as in Figure 3A, obtained 6 months after the patient was treated with 5-ASA rectal enemas. This biopsy is essentially within normal limits, and shows a normal crypt architectural pattern and an absence of inflammation in the lamina propria.

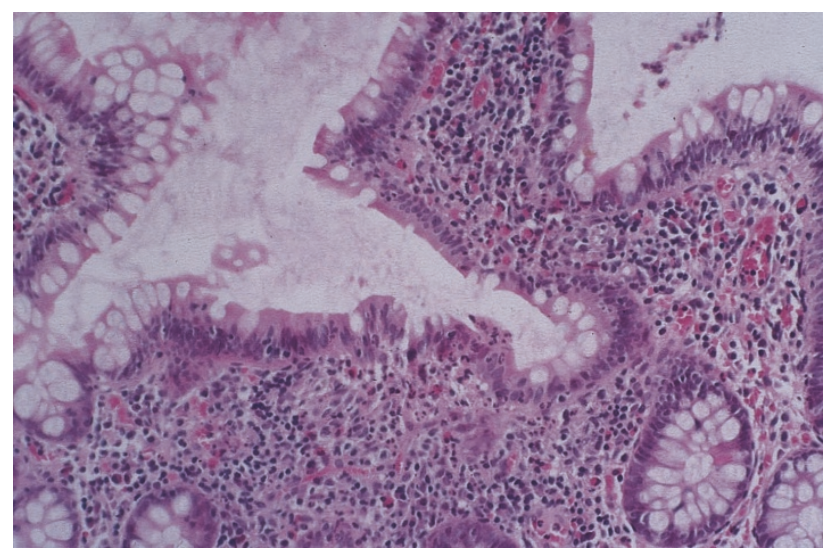

FIGURE 4. High power view of the distal terminal ileum in a patient with fulminant ulcerative colitis showing a mild degree of neutrophilic inflammation in the superficial lamina propria and superficial epithelium. This patient had no granulomas, fissuring ulceration, strictures or evidence of pyloric metaplasia in the ileum. The inflammation is focal and mild and only present in the distal few centimeters of ileum. In the appropriate clinical setting, these features have been interpreted as indicative of "backwash ileitis."

\section{Upper Gastrointestinal Involvement in UC}

Rarely, gastric and/or duodenal involvement, has been reported in association with clinically and pathologically confirmed UC (45-48). A recent study by Valdez et al. described 4 patients with chronic active inflammation in the duodenum similar in appearance to the patients' colonic disease (45). However, until these cases are followed up for longer intervals of time, it is difficult to know if the upper GI involvement actually represents a manifestation of UC, or simply an as yet unidentified associated disorder. More precise characterization of cases with long-term follow up is needed to help establish specific criteria for upper GI involvement in patients with UC.

\section{Unusual Patterns of Disease in Crohn's Disease}

Typical features of CD, such as granulomas, fissuring ulceration and transmural lymphoid aggregates, are seen less commonly in the colon compared to the small intestine. In fact, CD may involve the colon in a manner similar to UC, consisting of continuous mucosal inflammation of the colorectum, minimal or no submucosal inflammation, and an absence of upper GI involvement (49-52). In these cases, the diagnosis relies heavily on finding
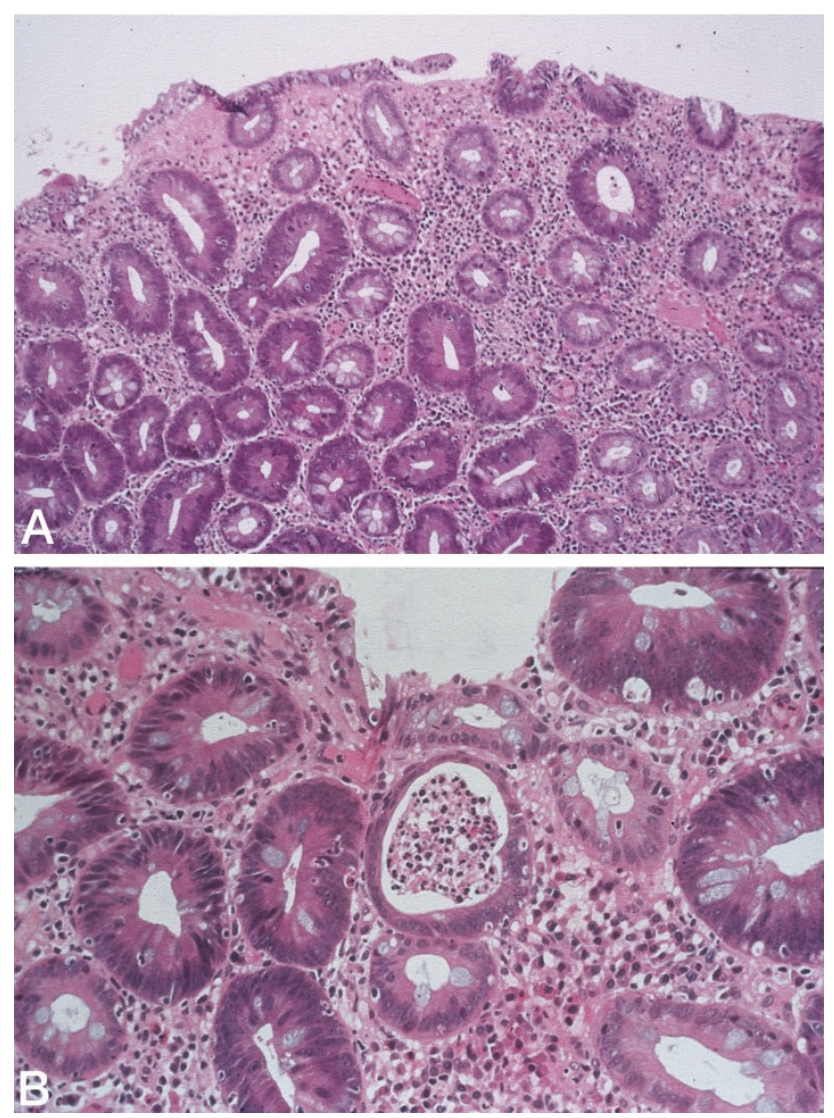

FIGURE 5. A, Medium power photograph of a polypoid dysplastic lesion arising in a patient with chronic ulcerative colitis. The polyp shows a mixture of low-grade dysplastic crypts and non-dysplastic crypts at the surface of the polyp. Note the increased inflammation in the lamina propria. B, High power view of a different area from the same polyp showing low-grade dysplastic crypts at the surface of the polyp with a crypt abscess. 
granulomas or transmural lymphoid aggregates in the resection specimen. However, more often than not, these cases follow a clinical course typical of $\mathrm{CD}$ and may account for some of the cases of presumed UC which have CD-like complications (53).

\section{Dysplasia in Ulcerative Colitis and Crohn's Disease}

\section{Dysplasia in Crohn's Disease}

Patients with inflammatory bowel disease are well known to have an increased risk for the development of adenocarcinoma (54-59). Although this risk is well established in patients with UC, there is less data available in CD. Several studies suggest that given a similar duration and extent of disease, the risk of colon cancer is similar in CD and UC (60-63). In CD, there is also an increased risk of adenocarcinoma in excluded segments of bowel and in the small intestine (57). In one study by Bernstein et al., the relative risk of colon cancer in CD and UC was 2.64 and 2.75, respectively (54).

Most studies also support the dysplasiacarcinoma sequence in CD $(55,57)$. For instance, in a study by Freidman et al., a screening and surveillance program detected dysplasia, or cancer, in $16 \%$ of 259 patients who had follow-up for a median of 24 months (55). Furthermore, the reported frequency of dysplasia in Crohn's patients with colorectal carcinoma ranges from $40-100 \%(64,65)$. In a review of Crohn's-related adenocarcinomas, $61 \%$ were found to have dysplasia in either the adjacent, or distant, colonic mucosa (57). Dysplasia in CD is morphologically similar to that seen in UC.

Overall, the survival benefit of endoscopic surveillance in $\mathrm{CD}$ is controversial, primarily due to the lack of prospective studies $(55,58,66,67)$. However, there is a growing trend toward endoscopic surveillance in patients with long standing CD (66). Unfortunately, surveillance is often difficult in this disorder due to the frequent presence of strictures. In $\mathrm{CD}$, up to $12 \%$ of strictures are malignant (67). Thus, from the standpoint of surveillance, colonoscopic examination often requires the use of a pediatric endoscope.

\section{Dysplasia in Ulcerative Colitis}

Incidence: The strongest risk factors for the development of carcinoma in UC are the extent and duration of disease (68-72). Some studies also suggest that sclerosing cholangitis represents a significant risk factor for cancer as well (73-75). Controversial risk factors include early age of onset, family history of colon cancer and folate deficiency (7678). It is generally accepted that patients who have had UC for at least seven to eight years are at risk for developing carcinoma and should be entered into a colonoscopic surveillance program $(58,68$,
79-81). The incidence of dysplasia in UC is difficult to estimate; studies suggest a $5 \%$ incidence of dysplasia after ten years and a $25 \%$ incidence after 20 years $(80,82-85)$. The cumulative incidence of colorectal cancer after 25-35 years of UC ranges from $3.1 \%$ to $43 \%$. A reasonable rule of thumb is that the risk of carcinoma increases approximately $1 \%-2 \%$ per year after the first ten years of disease.

Pathologic Features: It is widely accepted that cancer in UC progresses through a step-wise process from inflammation to dysplasia and carcinoma. Dysplasia, as defined by the inflammatory bowel disease-dysplasia morphology study group in 1983, is unequivocal neoplastic epithelium (86). Grossly, there are two general patterns; flat and raised $(87,88)$. Raised lesions, or dysplasia associated lesions or masses (DALMs), are graded similarly, but are treated differently from flat dysplasia, as discussed below. Atypical changes in UC are separated into three distinct categories: negative for dysplasia, indefinite for dysplasia, and positive for dysplasia. Epithelium that is considered dysplastic is further subclassified into low grade and high grade depending on the severity of the atypia. The morphologic criteria for dysplasia are reviewed by Riddell et al. (86).

Some of the problems encountered in the evaluation of dysplasia includes sampling error and interobserver variability in interpretation (86, 89-91). Since Riddell et al.'s study in 1983, several interobserver studies have shown only moderate levels of agreement (89-91). However, at this time, assessment of risk of malignancy in UC by other histochemical (mucins, sialosyn $\mathrm{TN}$ ), immunohistochemical (PCNA, MIB-1, p53) or molecular (APC, p27, p16, aneuploidy) methods have not been shown to be more effective than histologic evaluation of dysplasia (92-97).

Natural History and Treatment: Dysplasia is broadly categorized as flat, or associated with an endoscopic (gross) lesion (DALM) (87, 98-100). This subdivision is important since it has direct ramifications as to the risk of malignancy and the treatment of the patient (see Table 4). In brief, low-grade flat dysplasia has a low incidence of associated carcinoma in patients who have had a colectomy (less than 20\%). Furthermore, the natural history of low grade dysplasia is not fully understood and given that there is significant interobserver variability in interpretation of biopsies, most patients with flat low grade dysplasia are treated with increased surveillance $(58,68,79-81,101$, 102). However, recent data suggests that the fiveyear predictive value of low-grade dysplasia for the development of either high-grade dysplasia or cancer may be as high as $54 \%$ (85). Thus, many institutions now recommend colectomy for patients with flat low-grade dysplasia, particularly if it is 
TABLE 4. Treatment of Dysplasia in IBD

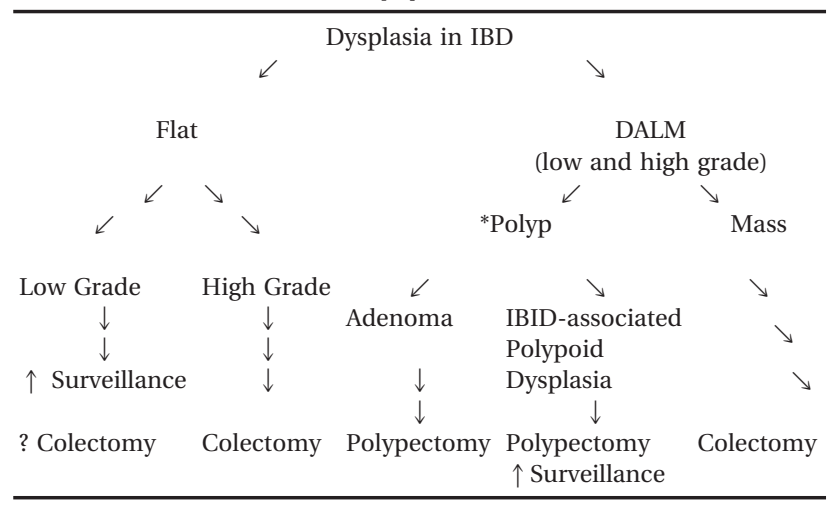

* Polyp implies benign dysplastic epithelium, well circumscribed, completely excised, and not associated with either flat dysplasia or carcinoma.

found on initial exam, is multifocal, or synchronous $(58,85)$. In contrast, flat high-grade dysplasia has a higher probability of coexistent cancer at colectomy $(40-67 \%)$ and of progression to carcinoma (40-90\% $2-5$ year predictive value) $(85,102)$. For these reasons, flat high-grade dysplasia is generally treated with colectomy. Patients with biopsies considered indefinite for dysplasia should have a repeat endoscopy in 6 months to 1 year, preferably at a time after the inflammation has subsided (58).

\section{DALM in Ulcerative Colitis}

General Comments: Any dysplastic lesion, either low or high grade, if associated with a polyp or mass (DALM), has traditionally been considered a strong indication for colectomy because of a high associated risk of carcinoma (40\%-50\%) $(88,98)$. However, this recommendation is based on some early studies that failed to recognize the different subtypes of DALMs that may be associated with UC (88, 98-100). In 1981, Blackstone et al. found 12 patients with macroscopic dysplastic lesions in a four year follow-up study of 112 UC patients (88). Seven of the 12 patients were found to have invasive carcinoma at the time of colectomy. These authors concluded that the gross finding of a dysplastic lesion on colonoscopy was an ominous sign that carried a high risk of cancer and, therefore, constituted a strong indication for colectomy. Certainly, for patients who have a dysplasia-associated mass, or a large polyp which is incompletely excised, colectomy is the most suitable form of treatment. However, few studies have addressed the clinical significance of isolated polypoid dysplastic lesions (similar in appearance to a sporadic adenoma) that arise on a background of UC. As a result, the treatment of isolated "adenoma-like" polypoid dysplastic lesions which have been totally excised, and contain no invasive cancer, until recently, has been controversial $(88,103)$. Is a simple polypectomy adequate treatment for these patients? Until recently $(87,104)$, there has been no data to help separate a sporadic adenoma, which happens to develop in a patient with UC, from a polypoid dysplastic lesion related to the underlying IBD. Clearly, the former lesion can be treated by simple polypectomy, whereas the latter should probably be treated with a colectomy (see below) (87).

Differential Diagnosis of UC-associated Polypoid Dysplasia vs. Sporadic Adenoma: In 1998, our group published the results of a retrospective study of 59 IBD patients (51 UC, $8 \mathrm{CD}$ ), all of whom had at least one benign polypoid dysplastic lesion excised, and in whom the differential diagnosis with an incidental sporadic adenoma was entertained (87). On the basis of our follow-up data, several clinical, endoscopic and pathologic features were significantly different between probable IBD-associated polypoid dysplastic lesions and sporadic adenomas (see Table 5). Histologically, polypoid dysplastic lesions associated with IBD appear similar to sporadic adenomas in terms of their overall architectural and cytologic features. However, polypoid dysplastic lesions have a higher degree of inflammation within the lamina propria, and usually show a mixture of normal and dysplastic crypts at the surface of the polyp (Table 5) (Fig. 5). Stalk dysplasia, if present, should alert the pathologist that dysplasia may be present in the adjacent mucosa and that they are likely dealing with an IBD-associated dysplastic lesion rather than an adenoma. Features such as size, architectural type (tubular, tubulovillous, villous), degree of dysplasia, and nuclear chroma-

TABLE 5. Summary of Differentiating Features between IBD-Associated Polypoid Dysplasia and Sporadic Adenomas

\begin{tabular}{|c|c|c|}
\hline Feature Dysplasia & Probable Adenoma & Probable Polypoid Dysplasia \\
\hline Patient age & Older ( $>60$ years) & Younger $(<50$ years $)$ \\
\hline Extent of disease & Usually subtotal & Usually total \\
\hline Disease activity & Usually inactive & Usually active \\
\hline Disease duration & Shorter $(<10$ yr $)$ & Longer $(>11$ yrs $)$ \\
\hline Polyp location & Usually non-diseased area [ $\uparrow$ right colon] & Diseased area [ $\uparrow$ left colon] \\
\hline Associated Flat Dysplasia & Never & Occasionally \\
\hline Increased lamina propria inflammation & Usually absent & Usually present \\
\hline Villous architecture & Usually absent & Occasionally present \\
\hline Mixture of benign and dysplastic crypts at surface of polyp & Usually absent & Usually present \\
\hline $\mathrm{LOH}$ of $3 \mathrm{P}$ & Uncommon & Common \\
\hline $\mathrm{LOH}$ of $\mathrm{P} 16$ & Rare & Common \\
\hline
\end{tabular}


tin pattern are not helpful in distinguishing these two groups of lesions.

IBD-associated polypoid dysplasia shows a different pattern of genotypic abnormalities (P53, $\beta$ catenin, APC, P16, 3P) compared to sporadic adenomas, and, thus, may provide a valuable means of distinguishing these lesions (103, 105-112). For instance, by immunohistochemistry, we have recently described a significantly higher degree of P53, and a lower degree of nuclear $\beta$ catenin immunostaining, in UC-associated polypoid dysplasia compared to sporadic adenomas (106). These techniques may be used in diagnostically difficult cases.

From a molecular point of view, a recent study of adenoma-like polypoid dysplastic lesions by Odze $e t$ $a l$. strongly supports the concept that these lesions have a different molecular genotype than non adenoma-like DALMs (108). For instance, regardless of their location either within or outside (proximal) to areas of colitis, adenoma-like polypoid dysplastic lesions showed a similar prevalence of 3p, APC and p16 mutations as non UC-associated sporadic adenomas. However, non adenoma-like DALMs from UC patients showed a significantly higher prevalence of $3 p$ and p16 mutations indicating a different timing of molecular events in these lesions. Based on these findings, we believe that adenoma-like polypoid dysplastic lesions in UC and "sporadic" adenomas represent the same pathobiologic entity.

Treatment of Adenoma-Like DALMS: There is compelling recent data to suggest that UC patients with an adenoma-like polypoid dysplastic lesion may be treated adequately by polypectomy and continued surveillance (113-115). In a recent study by our group (Engelsjerd et al.) the clinical outcome of 24 UC patients with an adenoma-like polypoid dysplastic lesion were compared to 10 UC patients with a coincidental sporadic adenoma (based on tumor location proximal to colitis) and 49 non-UC (control) patients with a sporadic adenoma (114). After more than 3 years of follow-up, $58 \%$ of UC patients with an adenoma-like lesion developed further adenoma-like polyps, which was statistically similar to the $50 \%$ of UC patients with sporadic adenomas and the $39 \%$ of control group patients who developed further adenomas. Only 1 UC patient with an adenoma-like polyp developed an isolated focus of low-grade dysplasia and none developed adenocarcinoma. Dramatically similar results were found by Rubin et al. in a study of $30 \mathrm{UC}$ patients and $18 \mathrm{CD}$ patients with 70 "dysplastic polyps" all of whom were treated with polypectomy (mean follow-up:4.1 years) (115). Most patients $(52 \%)$ did not develop any further polyps and none developed either dysplasia or adenocarcinoma. As a result of these studies, a new proposal for the treatment of adenoma-like polypoid dysplastic lesions has been proposed and is outlined in Table 6 .
TABLE 6. Treatment of DALM's in Ulcerative Colitis

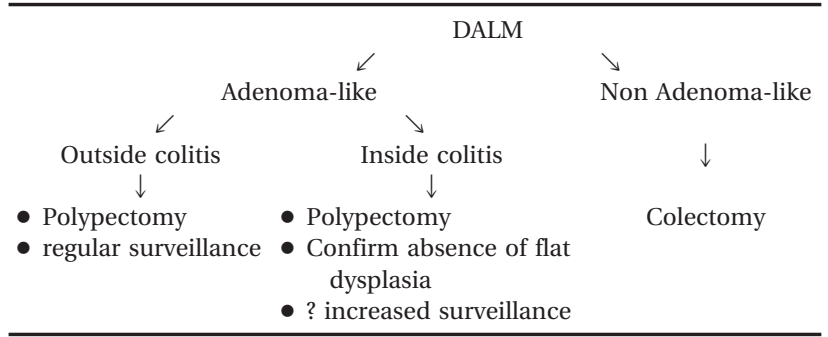

\section{REFERENCES}

1. Berre NL, Heresbach D, Kerbaol M, et al. Histological discrimination of idiopathic inflammatory bowel disease from other types of colitis. J Clin Pathol 1995;48:749-53.

2. Caroline DF, Evers K. Colitis: radiographic features and differentiation of idiopathic inflammatory bowel disease. Radiol Clin North Am 1987;25(1):47-66.

3. Tanaka M, Riddell RH. The pathological diagnosis and differential diagnosis of Crohn's disease. Hepato-gastroenterol 1990;37:18-31.

4. Geboes K. Crohn's disease, ulcerative colitis or indeterminate colitis-how important is it to differentiate? Acta Gastroenterol Belg 2001;64:197-200.

5. Nicholls RJ, Wells AD. Indeterminate colitis. Bailliere's Clin Gastroenterol 1992;6:105-12.

6. Yu CS, Pemberton JH, Larson D. Ileal pouch-anal anastomosis in patients with indeterminate colitis. Dis Colon Rectum 2000;43:1487-96.

7. Farmer M, Petras RE, Hunt LE, et al. The importance of diagnostic accuracy in colonic inflammatory bowel disease. Am J Gastroenterol 2000;95:3184-8.

8. Marcello PW, Schoetz DJ, Roberts PL, et al. Evolutionary changes in the pathologic diagnosis after the ileoanal pouch procedure. Dis Colon Rectum 1997;40:263-9.

9. Meucci G, Bortoli A, Riccioli FA, et al. Frequency and clinical evolution of indeterminate colitis: a retrospective multi-centre study in northern Italy. Eur J Gastroenterol Hepathol 1999;11:909-13.

10. Swan NC, Goeghan JG, O'Donoghue DP, et al. Fulminant colitis in inflammatory bowel disease. Dis Colon Rectum 1998;41:1511-5.

11. Sagar PM, Dozois RR, Wolff BG. Long-term results of ileal pouch-anal anastomosis in patients with Crohn's disease. Dis Colon Rectum 1996;39:893-8.

12. Grobler SP, Hosie KB, Affie E, et al. Outcome of restorative proctocolectomy when the diagnosis is suggestive of Crohn's disease. Gut 1993;34:1384-8.

13. Wells AD, McMillan I, Price AB, et al. Natural history of indeterminate colitis. Br J Surg 1991;78:179-81.

14. McIntyre PB, Pemberton JH, Wolff BG, et al. Indeterminate colitis; long term outcome in patients after ileal pouch-anal anastomosis. Dis Colon Rectum 1995;38(1):51-4.

15. Pezim ME, Pemberton JH, Beart RW Jr., et al. Outcome of "indeterminante" colitis following ileal pouch-anal anastomosis. Dis colon Rectum 1989; 32:653-8.

16. Koltun WA, Schoetz DJ, Roberts PL, et al. Indeterminate colitis predisposes to perineal complications after ileal pouch-anal anastomosis. Dis Colon Rectum 1991;34:857-60.

17. Riegler G, Arimoli A, Esposito P, et al. Clinical evolution in an outpatient series with indeterminate colitis. Dis Colon Rectum 1997;40:437-9.

18. Kangas E, Matikainen M, Mattila J. Is "Indeterminate colitis” Crohn's disease in the long-term follow-up? Int Surg 1994;79:120-3. 
19. Papadakis KA, Targan SR. Serologic testing in inflammatory bowel disease: its value in indeterminate colitis. Cur Gastroenterol Rep 1999;1:482-5.

20. Odze R, Antonioli D, Peppercorn M, et al. Effect of topical 5-aminosalicylic acid (5-ASA) therapy on rectal mucosal biopsy morphology in chronic ulcerative colitis. Am J Surg Pathol 1993;17:869-75.

21. Kleer CG, Appelman HD. Ulcerative colitis: patterns of involvement in colorectal biopsies and changes with time. Am J Surg Pathol 1998;22:983-9.

22. Bernstein CN, Shanahan F, Anton PA, et al. Patchiness of mucosal inflammation in treated ulcerative colitis: a prospective study. Gastrointest Endosc 1995;42:232-7.

23. Kim B, Barnett JL, Kleer CG, et al. Endocopic and histological patchiness in treated ulcerative colitis. Am J Gastroenterol 1999;94:3259-62.

24. D'Haens G, Geboes K, Peeters M, et al. Patchy cecal inflammation associated with distal ulcerative colitis: a prospective endoscopic study. Am J Gastroenterol 1997;92:1275-9.

25. Okawa K, Aoki T, Sano K, et al. Ulcerative colitis with skip lesions at the mouth of the appendix: a clinical study. Am J Gastroenterol 1998;93:2405-10.

26. Yang SK, Jung HY, Kang GH, et al. Appendiceal orifice inflammation as a skip lesion in ulcerative colitis: an analysis in relation to medical therapy and disease extent. Gastrointest Endosc 1999;49:743-7.

27. Mutinga M, Farraye F, Wang H, Odze RD. Clinical significance of right colonic inflammation in patients with left sided chronic ulcerative colitis: A study of 34 patients. Gastroenterology 2001;120:A450.

28. Ekbom A, Helmick C, Zack M, et al. The epidemiology of inflammatory bowel disease: a large, population-based study in Sweden. Gastroenterology 1991;100:350-8.

29. Pena AS, Meuwissen SGM. Evidence for clinical subgroups in inflammatory bowel disease. In: Targan S, Shanahan D, editors. Inflammatory bowel disease, from bed to bedside. Baltimore: Williams \& Wilkins; 1994. pp. 272-8.

30. Davison AM, Dixon MF. The appendix as a 'skip lesion' in ulcerative colitis. Histopathology 1990;16:93-5.

31. Groisman GM, George J, Harpaz N. Ulcerative appendicitis in universal and nonuniversal ulcerative colitis. Mod Pathol 1994;7:322-5.

32. Kroft SH, Stryker SJ, Rao MS. Appendiceal involvement as a skip lesion in ulcerative colitis. Mod Pathol 1994;7:912-4.

33. Goldblum JR, Appelman HD. Appendiceal involvement in ulcerative colitis. Mod Pathol 1992;5:607-10.

34. Markowitz J, Kahn E, Grancher K, et al. Atypical rectosigmoid histology in children with newly diagnosed ulcerative colitis. Am J Gastroenterol 1993;88:2034-7.

35. Glickman J, Bousvaros A, Farraye F. Relative rectal sparing and skip lesions are not uncommon at initial presentation in pediatric patients with chronic ulcerative colitis. USCAP 2002. Mod Pathol 2002;15:127A.

36. Washington K, Crissinger K, Lauwers G. Histopathology of ulcerative colitis in initial rectal biopsy in children. Mod Pathol 2000;90A.

37. Robert ME, Skacel M, Ullman T, et al. Histologic rectal sparing (RS) at initial presentation of ulcerative colitis (UC). Mod Pathol 2000;13:87A.

38. Tang LH, Reyes-Mugica M, Hao L, et al. Histologic differences between children and adults presenting with ulcerative colitis. Mod Pathol 2000;14:96A.

39. Schumacher G, Kollberg B, Sandstedt B. A prospective study of first attacks of inflammatory bowel disease and infectious colitis. Histologic course during the 1st year after presentation. Scan J Gastroenterol 1994;29:318-32.

40. McCready FJ, Bargen A, Dockerty MB, et al. Involvement of the ileum in chronic ulcerative colitis. N Engl J Med 1949; 240:119-27.
41. Saltzstein SL, Rosenberg BF. Ulcerative colitis of the ileum, and regional enteritis of the colon: a comparative histopathologic study. Am J Clin Pathol 1963;40:610-23.

42. Schlippert W, Mitros F, Schulze K. Multiple adenocarcinomas and premalignant changes in "backwash" ileitis. Am J Med 1979;66:879-82.

43. Gustavsson S, Weiland LH, Kelly KA. Relationship of backwash ileitis to ileal pouchitis after ileal pouch-anal anastomosis. Dis colon Rectum 1987;30:25-8.

44. Heuschen UA, Hinz U, Allemeyer EH, et al. Backwash ileitis is strongly associated with colorectal carcinoma in ulcerative colitis. Gastroenterology 2001;120:841-7.

45. Valdez R, Appelman HD, Bronner MP, et al. Diffuse duodenitis associated with ulcerative colitis. Am J Surg Pathol 2000;24:1407-13.

46. Igarashi M, Hirokado K, Suziki Y, et al. A case report of ulcerative colitis complicated with ulcerative duodenitis. Journal of Japan Society of Colo-Proctology Colitis 1984;37:255-60.

47. Sasaki M, Okada K, Koyama S, et al. Ulcerative colitis complicated by gastroduodenal lesions. J Gastroenterol 1996;31: $585-9$.

48. Mitomi H, Atari E, Eusugi H, et al. Distinctive diffuse duodenitis associated with ulcerative colitis. Dig Dis Sci 1997; 42:684-93.

49. McQuillan AC, Appelman HD. Superficial Crohn's disease: a study of 10 patients. Surg Pathol 1989;2:231-9.

50. Guy TS, Williams NN, Rosato EF. Crohn's disease of the colon. Surg Clin North Am 2001;81:159-68.

51. Kleer CG, Appelman HD. Surgical Pathology of Crohn's disease. Surg Clin North Am 2001;81:13-30.

52. Harpas N, Friedman S, Geoge J. Significant Crohn's colitis. Pathological and clinical features indicating long term follow-up. Mod Pathol 2001;14:86A.

53. Goldstein NS, Sandford WW, Bodzin JH. Crohn's-like complications in patients with ulcerative colitis after total proctocolectomy and ileal pouch-anal anastomosis. Am J Sur Pathol 1997;21:1343-53.

54. Bernstein CN, Blanchard JF, Kliewer E, et al. Cancer risk in patients with inflammatory bowel disease: a populationbased study. Cancer 2001;91:854-62.

55. Friedman S, Rubin PH, Bodian C, et al. Screening and surveillance colonoscopy in chronic Crohn's colitis. Gastroenterology 2001;120:820-6.

56. Stahl TJ, Schoetz DJ Jr, Roberts PL, et al. Crohn's disease and carcinoma: increasing justification for surveillance? Dis Colon Rectum 1992;35:850-6.

57. Sigel JE, Petras RE, Lashner BA, et al. Intestinal adenocarcinoma in Crohn's disease: a report of 30 cases with a focus on coexisting dysplasia. Am J Surg Pathol 1999;23:651-5.

58. Itzkowitz SH. Inflammatory bowel disease and cancer. Gastroenterol Clin North Am 1997;26:129-39.

59. Kilgore SP, Sigel JE, Goldblum JR. Hyperplastic-like mucosal change in Crohn's disease: an unusual form of dysplasia? Mod Pathol 2000;13:797-801.

60. Ekbom A, Helmick C, Zack M, Adami HO. Increased risk of large-bowel cancer in Crohn's disease with colonic involvement. Lancet 1990;336:357.

61. Rubio CA, Befrits R. Colorectal adenocarcinoma in Crohn's disease: A retrospective histologic study. Dis Colon rectum 1997;40:1072.

62. Greenstein AJ, Sachar DB, Smith H, et al. Comparison of cancer risk in Crohn's disease and ulcerative colitis. Cancer 1981;48:2742.

63. Gyde SN, Prior P, Macarteney JC, et al. Malignancy in Crohn's disease. Gut.;1980;21:1024.

64. Connell WR, Sheffield JP, Kamm MA, et al. Lower gastrointestinal malignancy in Crohn's disease. Gut 1994;35:347-52.

65. Hamilton SR. Colorectal carcinoma in patients with Crohn's disease. Gastroenterology 1985;89:398-407. 
66. Hanauer SB, Meyers. Practice guidelines. Management of Crohn's disease in adults. Am J Gastroenterol 1997;92:559.

67. Yamazaki Y, Ribeiro MB, Sachar DB, et al. Malignant colorectal strictures in Crohn's disease. Am J Gastroenterol 1991;86:882.

68. Bernstein CN. Cancer surveillance in inflammatory bowel disease. Curr Gastroenterol Rep 1999;1:496-504.

69. Ekbom A, Helmick C, Zack M, Adami H. Ulcerative colitis and colorectal cancer: a population-based study. N Engl J Med 1990;323:1228-33.

70. Lennard-Jones JE, Melvill DM, Morson BC, et al. Precancer and cancer in extensive ulcerative colitis: findings among 401 patients over 22. Gut 1990;31:800-6.

71. Greenstein AJ, Sachar DB, Smith H, et al. Cancer in universal and left-sided ulcerative colitis: Factors determining risk. Gastrenterology 1979;77:290-4.

72. Collins JH, Feldman M, Fordtran JS. Colon cancer, dysplasia and influence of surveillance in patients with ulcerative colitis. N Engl J Med 1987;316:1654-8.

73. Brentnall TA, Haggitt RC, Rabinovitch PS, et al. Risk and natural history of colonic neoplasia in patients with primary sclerosing cholangitis and ulcerative colitis. Gastroenterology 1996;110:331-8.

74. Shetty K, Rybicki L, Brezinski A, et al. The risk of cancer or dysplasia in ulcerative colitis patients with primary sclerosing cholangitis. Am J Gastroenterol 1999;94:1643-9.

75. D'Haens GR, Lashner BA, Hanauer SB. Pericholangitis and sclerosing cholangitis are risk factors for dysplasia and cancer in ulcerative colitis Am J Gastroenterol 1993;88:1174-8.

76. Sugita A, Sachar DB, Bodian C, et al. Colorectal cancer in ulcerative colitis: Influence on anatomical extent and age at onset on colitis-cancer interval. Gut 1991;32:167-9.

77. Nuako KW, Ahlquist DA, Mahoney DW, et al. Familial predisposition for colorectal cancer in chronic ulcerative colitis: A case-control study. Gastroenterology 1998;115:1079-82.

78. Lashner BA, Silverstein MD, Hanauer SB. Hazard rates for dysplasia and cancer in ulcerative colitis: result from a surveillance program. Dig Dis Sci 1989;34:1536.

79. Nugent FW, Haggitt RC, et al. Cancer surveillance in ulcerative colitis. Gastroenterology 1991;100:1241-8.

80. Woolrich AJ, DaSilva MID, et al. Surveillance in the routine management of ulcerative colitis: the prediction value of low-grade dysplasia. Gastroenterology 1992;103:431-8.

81. Lennard-Jones JE, Morson BC, Ritchie JK, et al. Cancer surveillance in ulcerative colitis. Experience over 15 years. Lancet ii 1983:149-52.

82. Rozen P, Baratz M, Fefer F, et al. Low incidence of significant dysplasia in a successful endoscopic surveillance program of patients with ulcerative colitis. Gastroenterology 1995;108:1361-70.

83. Kewenter J, Ahiman H, Hulten L. Cancer risk in extensive ulcerative colitis. Annu Surg 1987;188:824-8.

84. Langholz E, Munkholm P. Davidsen M, et al. Colorectal cancer risk and mortality in patients with ulcerative colitis. Gastroenterology 1992;103:1444-51.

85. Connell WR, Lennard-Jones JE, Williams CB, et al. Factors affecting the outcome of endoscopic surveillance for cancer in ulcerative colitis. Gastroenterology 1994;107:934-44.

86. Riddell RH, Goldman H, Ransohoff DF, et al. Dysplasia in inflammatory bowel disease: standardized classification with provisional clinical applications. Hum Pathol 1983;14:931-68.

87. Torres C, Antonioli D, Odze RD. Polypoid dysplasia and adenomas in inflammatory bowel disease. Am J Surg Pathol 1998;22:275-84.

88. Blackstone MO, Riddell RH, Rogers BHG, et al. Dysplasiaassociated lesion or mass (DALM) detected by colonoscopy in long-standing ulcerative colitis: an indication for colectomy. Gastroenterology 1981;8:366-74.
89. Odze RD, Goldblum JR, Noffsinger A. Interobserver variability in the diagnosis of ulcerative colitis-associated dysplasia by telepathology. USCAP 2002. Mod Pathol 2002;15:140A.

90. Dixon MF, Brown LJR, Gilmour HM, et al. Observer variation in the assessment of dysplasia in ulcerative colitis. Histopathology 1988;13:385-97.

91. Melville DM, Jass JR, Morson BC, et al. Observer study on the grading of dysplasia in ulcerative colitis; comparison with clinical outcome. Hum Path 1990;20:1008-14.

92. Burmer GC, Rabinovitch PS, Haggitt RC, et al. Neoplastic progression in ulcerative colitis: histology, DNA content, and loss of a p53 allele. Gastroenterology 1992;103:1602.

93. Lofberg R, Brostom O, Karlen P, et al. DNA aneuploidy in ulcerative colitis: Reproducibility, topographic distribution, and relation to dysplasia. Gastroenterology 1992;102:1149.

94. Itzkowitz SH, Young E, Dubois D, et al. Sialosyl-Tn antigen is prevalent and precedes dysplasia in ulcerative colitis: a retrospective case-control study. Gastroenterology 1996;110:694.

95. Itzkowitz SH, Greenwald B, Meltzer SJ. Colon carcinogenesis in inflammatory bowel disease. Inflamm Bowel Dis 1995;1:142.

96. Greenwald BD, Harpaz N, Yin J, et al. Loss of heterozygosity affecting the p53, Rh, and mmc/apc tumor supressor gene loci in dysplastic and cancerous ulcerative colitis. Cancer Res 1992;52:741.

97. Rubin CE, Haggitt RC, Burmer GC, et al. DNA aneuploidy in colonic biopsies predicts future development of dysplasia in ulcerative colitis. Gastroenterology 1992;103:1611.

98. Butt JH, Konishi F, Morson BC, et al. Macroscopic lesions in dysplasia and carcinoma complicating ulcerative colitis. Dig Dis Sci 1983;28:18-26.

99. Rubio CA, Johansson C, Slezak P, et al. Villous, dysplasia: an ominous histologic sign in colitic patients. Dis Colon Rectum 1984;27:283-7.

100. Tytgat GNJ, Dhir V, Gopinath N. Endoscopic appearance of dysplasia and cancer in inflammatory bowel disease. Eur J Cancer, 1995;31(7/8):1174-7.

101. Levin B, Lennard-Jones J, Riddell RH, et al. Surveillance of patients with chronic ulcerative colitis. WHO collaborating centre for the prevention of colorectal cancer. Bull World Health Organ 1991;69:121-6.

102. Bernstein CN, Shanahan F, Weinstein WM. Are we telling patients the truth about surveillance colonoscopy in ulcerative colitis? Lancet 1994;343:71-4.

103. Odze RD. Adenomas and adenoma-like DALMs in chronic ulcerative colitis: a clinical, pathologic, and molecular review. Am J Gastroenterol 1999;94:1746-50.

104. Schneider A, Stolte M. Differential diagnosis of adenomas and dysplastic Lesions in patients with ulcerative colitis. Z Gastroenterol 1993;31:653-6.

105. Fogt F, Vortmeyer AO, Stolte M, et al. Loss of heterozygosity of the von Hippel Lindau gene locus in polypoid dysplasia but not flat dysplasia in ulcerative colitis or sporadic adenomas. Human Pathol 1998;29:961-4.

106. Walsh SV, Loda M, Torres CM, et al. P53 and $\beta$ catenin expression in chronic ulcerative colitis-associated polypoid dysplasia and sporadic adenomas: an immunohistochemical study. Am J Surg Pathol 1999;23:963-9.

107. Fogt F, Vortmeyer AO, Goldman H, et al. Comparison of genetic alterations in colonic adenoma and ulcerative colitis-associated dysplasia and carcinoma. Hum Pathol 1988;29:131-6.

108. Odze R, Brown CA, Noffsinger AE, et al. Genetic alterations in chronic ulcerative colitis associated adenoma-like DALMs are similar to non-colitic sporadic adenomas. Am J Surg Pathol 2000;24:1209-16.

109. Kern SE, Redston M, Seymour AB, et al. Molecular genetic profiles of colitis- associated neoplasms. Gastroenterology 1994;107:420-8. 
110. Tarmin L, Yin J, Harpaz N, et al. Adenomatous polyposis coli gene mutations in ulcerative colitis-associated dysplasias and cancers versus sporadic colon neoplasms. J Cancer Research 1995;55:2035-8.

111. Willenbucher RF, Zelman SJ, Ferell LD, et al. Chromosomal alterations in ulcerative colitis-related neoplastic progression. Gastroenterology 1997;113:791-801.

112. Yin J, Harpaz N, Tony Y, et al. p53 point mutations in dysplastic and cancerous ulcerative colitis lesions. Gastroenterology 1993;104:1633-9.
113. Medlicott SAC, Jewell LD, Price L, et al. Conservative management of small adenomata in ulcerative colitis. Am J Gastroenterol 1997;92:2094-8.

114. Engelsgjerd M, Farraye F, Odze RD. Polypectomy may be adequate treatment for adenoma- like dysplastic lesions in chronic ulcerative colitis. Gastroenterology 1999;117:1288-94.

115. Rubin PH, Friedman S, Harpaz N, et al. Colonoscopic polypectomy in chronic colitis: conservative management after endoscopic resection of dysplastic polyps. Gastroenterology 1999;117:1295-300. 